\title{
P02-2-8 Poster session
}

\section{Downregulation of spinal astrocytic connexin43 leads to mechanical hypersensitivity through upregulation of interleukin-6 and cyclooxygenase- 2 in mice}

\author{
Norimitsu Morioka, Syun Kondo, Yoki Nakamura, Kazue Hisaoka-Nakashima, Yoshihiro Nakata \\ Pharmacology, Hiroshima University Graduate School of Biomedical \& Health Sciences, Japan
}

\section{Backgrounds}

Connexin43 ( $\mathrm{Cx} 43)$ is expressed in spinal dorsal horn astrocytes and crucial in the maintenance of neuropathic pain. Downregulation of spinal astrocytic $\mathrm{Cx} 43$ enhances glutamatergic neurotransmission, resulting in cutaneous hypersensitivity in mice. Decreased expression of astrocytic $\mathrm{Cx}_{\mathrm{x}} 43$ could lead to altered expression of other nociceptive molecules. Then, the current study has elaborated mechanisms mediating nociceptive hypersensitivity due to $\mathrm{Cx}_{\mathrm{x}} 43$ downregulation.

\section{Methods}

Primary spinal astrocytes were prepared from the spinal cord of neonatal Wistar rats. Knockdown of Cx43 in cultured astrocytes and spinal dorsal horn of ddy mice were performed by using RNA interference. Expression levels of mRNA or protein were measured by real-time PCR or Western blot, respectively. The withdrawal threshold of the hind paw to mechanical stimulation was determined using von Frey filaments.

\section{Results}

Transfection of $\mathrm{Cx} 43$-targeting siRNA in cultured spinal astrocytes increased expression of the pronociceptive cytokine interleukin-6 (IL-6) and the prostaglandin synthesizing enzyme cyclooxygenase-2 (COX-2). Increased expression of IL-6 and COX-2 was due to decreased $\mathrm{C}_{x} 43$ expression rather than due to diminished $\mathrm{Cx}_{4} 43$ channel function. In mice, downregulation of spinal $\mathrm{Cx}_{\mathrm{X}} 43$ expression by intrathecal treatment with $\mathrm{Cx}_{\mathrm{X}} 43$-targeting siRNA increased IL-6 and COX-2 expression and induced hind paw mechanical hypersensitivity. Connexin43 siRNA-induced mechanical hypersensitivity was attenuated by intrathecal treatment with anti-IL-6 neutralizing antibody and intraperitoneal treatment of selective COX-2 inhibitor celecoxib. Suppression of glycogen synthase kinase-3 $\beta$ (GSK-3 $\beta$ ), a serine/threonine protein kinase, prevented upregulation of IL- 6 and COX-2 expression induced by $\mathrm{Cx} 43$ downregulation in both cultured astrocytes and in mouse spinal dorsal horn. Inhibition of spinal GSK-3 $\beta$ also ameliorated Cx43 siRNA-induced mechanical hypersensitivity.

\section{Conclusions}

The current findings indicate that downregulation of spinal astrocytic $\mathrm{Cx}_{\mathrm{X}} 43$ leads to changes in expression of IL-6 and COX-2 underlying the maintenance of pain following peripheral nerve injury. 